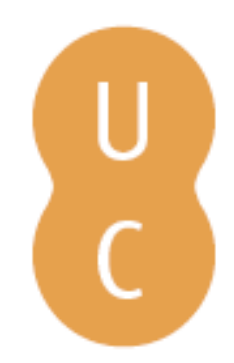

\title{
pompalina
}

\section{Ciência da informação: que filosofia?}

Autor(es): $\quad$ Ferreira, Carla; Lopes, Leonor; Grilo, Maria Elisa; Savioli, Vânia

Publicado por: Imprensa da Universidade de Coimbra

URL

persistente: URI:http://hdl.handle.net/10316.2/31967

DOI: $\quad$ DOI:http://dx.doi.org/10.14195/978-989-26-0869-3_41

Accessed : $\quad$ 26-Apr-2023 11:08:53

A navegação consulta e descarregamento dos títulos inseridos nas Bibliotecas Digitais UC Digitalis, UC Pombalina e UC Impactum, pressupõem a aceitação plena e sem reservas dos Termos e Condições de Uso destas Bibliotecas Digitais, disponíveis em https://digitalis.uc.pt/pt-pt/termos.

Conforme exposto nos referidos Termos e Condições de Uso, o descarregamento de títulos de acesso restrito requer uma licença válida de autorização devendo o utilizador aceder ao(s) documento(s) a partir de um endereço de IP da instituição detentora da supramencionada licença.

Ao utilizador é apenas permitido o descarregamento para uso pessoal, pelo que o emprego do(s) título(s) descarregado(s) para outro fim, designadamente comercial, carece de autorização do respetivo autor ou editor da obra.

Na medida em que todas as obras da UC Digitalis se encontram protegidas pelo Código do Direito de Autor e Direitos Conexos e demais legislação aplicável, toda a cópia, parcial ou total, deste documento, nos casos em que é legalmente admitida, deverá conter ou fazer-se acompanhar por este aviso. 
Maria Manuel Borges

Elias Sanz Casado

Coordenação

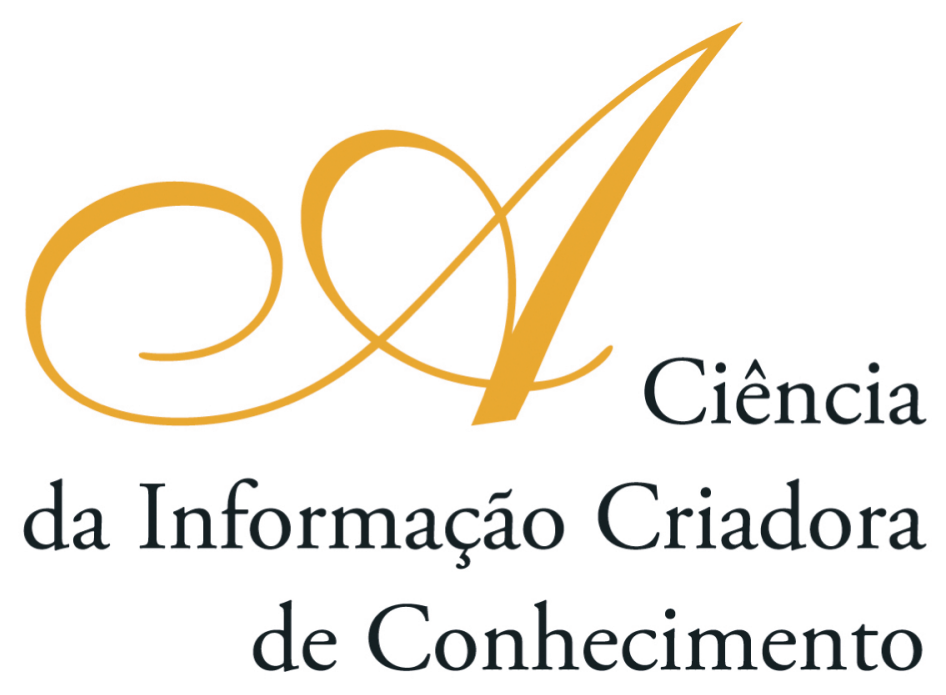

Vol. I I

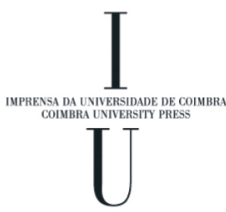

- COImbra 2009 


\title{
CiênCia da Informação: QUe Filosofia?
}

\author{
Carla Ferreira
}

Universidade de Coimbra (Portugal)

Leonor Lopes

Direção Regional de Cultura do Centro (Portugal)

Maria Elisa Grilo

Escola Superior de Educação de Coimbra (Portugal)

Vânia Savioli

\section{Introdução}

Se vivemos na era da informação, que coisa é esta que caracteriza uma época?

A resposta à questão: "O que é a informação?” está longe de estar esgotada. Falamos dela, mas não somos capazes de a definir por inteiro. Será que esta indizibilidade é mais uma das suas características? Será que a informação está em tudo e tudo é (ou tem) informação? Do que não restam dúvidas é de que a sociedade humana não pode prescindir dela. A Ciência da Informação (CI) ocupa, neste contexto, um lugar cimeiro, uma vez que é a ciência que estuda e analisa a forma como a informação é produzida, desenvolvida, organizada, armazenada, recuperada, disseminada, avaliada e gerida.

A relação entre informação e o sujeito que a detém e a relação que a pessoa informada vai ser capaz de estabelecer com o mundo que a rodeia poderão ser a razão pertinente que faz deste objecto fugidio o centro de tantas atençôes.

De que instrumentos, de que métodos, disciplina ou ciência precisamos para compreender a informação? Se no dizer de Saint-Exupéry "Uma pessoa para compreender tem de se transformar", que matéria é esta que queremos apreender e nos faz ser outros?

\section{Objectivos e Metodologia}

O objectivo deste trabalho é apresentar a posição de Luciano Floridi relativamente ao tipo de filosofia que poderá servir como suporte teórico à CI, contribuindo, na medida do possível, para o esclarecimento e debate de ideias no âmbito da cintura de disciplinas que gravitam em torno do objecto informaçâo, mais concretamente, no âmbito da CI.

A metodologia adoptada passou por uma análise de estudos publicados e por um extenso e reflectido trabalho de síntese. Pretendemos com esta metodologia evidenciar as dificuldades na definição de informação e, consequentemente, de ciência da informação. Estas dificuldades, que residem na interdisciplinaridade da CI e na inefabilidade do seu 
objecto, podem vir a ser ultrapassadas com a apropriação de uma filosofia emergente: a Filosofia da Informação (FI).

Mais do que procurar argumentar a FI como sendo a filosofia da CI, é nosso objectivo apresentar e caracterizar esta filosofia emergente (cujo surgimento é justificado pelo estabelecimento da Sociedade da Informação) e trazê-la para o debate epistemológico da CI.

\section{Resultados e Discussão}

Segundo Floridi (2002), a FI é um campo filosófico relacionado com a investigação crítica da natureza conceptual e dos princípios básicos da informação (incluindo a sua dinâmica, utilização e ciências), com a elaboração de metodologias teóricas informacionais e computacionais e com a aplicação destas a problemas filosóficos.

Ilharco (2003) vê na FI a possibilidade e o potencial de esta vir a constituir-se como a primeira área da filosofia que pensa, reflecte e questiona os vários tipos de investigação, de aplicação e de desenvolvimentos filosóficos ou científicos relacionados com o fenómeno informação.

Se assim for, será na FI que a CI irá beber os seus fundamentos teóricos e não na Epistemologia Social (ES) onde, e segundo Floridi (2002), a Library and Information Science (LIS) tem ido buscar a sua fundamentação teórica. Este facto terá contribuído para a crise de identidade que a LIS tem atravessado.

A razão pela qual Floridi (2002) defende que a LIS deve assentar os seus princípios fundamentais na FI e não na ES, tem a ver com o facto de a LIS operar a um nível mais fundamental do que o epistemológico: o objecto da LIS não é o conhecimento em si, mas as fontes de informação que o tornam possível, mesmo que apenas indirectamente.

Floridi fundamenta a sua posição afirmando que a ES pode referir-se a dois campos distintos de investigação: a Sociologia do Conhecimento (SC), que é a memória descritiva e estudo empírico das causas históricas e as condiçôes do conhecimento; e a Epistemologia Social do Conhecimento (ESC), que é o estudo crítico e conceptual das dimensões sociais do conhecimento.

Diferentemente de SC, a LIS tem uma posição normativa e, portanto, exige mais do que uma abordagem puramente descritiva. A biblioteca, por exemplo, é um lugar onde necessidades educacionais e de comunicação e os valores são implementados, onde conteúdos são avaliados e seleccionados para o público e em que práticas como a catalogação, por exemplo, estão longe de ser neutras e livres de avaliação. Esta situaçáo normativa afasta a LIS da ESC.

Perante este desajuste da ES como fundamentação teórica da LIS, Floridi (2002) avança com uma nova teoria: a LIS aplicada como FI seria a disciplina interessada nos documentos, nos seus ciclos e nos procedimentos, técnicas e dispositivos, através dos quais estes são implementados, geridos e regulamentados. A LIS aplica os princípios fundamentais e técnicas gerais de FI para resolver, definir e lidar com problemas práticos e com fenómenos específicos e concretos. Realiza objectivos práticos (por exemplo, conservação, valorização, educação, pesquisa, comunicação e cooperação), contribuindo, assim, para o desenvolvimento da investigação fundamental na FI. 
Entendida como uma filosofia funcional de análise e design da informação, a FI pode explicar e orientar a construção significativa do nosso ambiente intelectual e fornecer o tratamento sistemático das bases conceptuais da sociedade contemporânea.

Segundo o autor, se partirmos do princípio de que a LIS recorre à FI e que esta pode dar-lhe uma fundamentação teórica, a questão seguinte é saber como ambas podem interagir mais especificamente. Uma abordagem da FI à LIS é poder trabalhar nas ontologias dos objectos de estudo da LIS, construindo uma teoria dinâmica da informação e trabalhando o lado ético da informação.

A FI não pretende substituir a LIS. De facto elas não olham para o objecto informação de igual modo. Em comum têm o facto de desenvolverem a sua actividade em torno desse objecto, tal como outras ciências (por exemplo, a Informática). O estudo que estas ciências fazem da informação não é igual mas complementar.

Agora é o tempo de fazer uma nova reflexão sobre a informação: a FI pode ser a janela aberta para uma melhor compreensão dessa realidade antiga e sempre renovada, pela sua razão de ser e estar na sociedade contemporânea, senão a única para responder aos novos desafios éticos que hoje se colocam.

\section{Referências bibliográficas}

Floridi, Luciano (2002). On defining library and information science as applied philosophy of information. Social epistemology. 16:1, 37-49. Retrieved from http://www. philosophyofinformation.net/publications/pdf/isaspi.pdf

Ilharco, Fernando (2003). Filosofia da Informação: uma introdução à informação como fundamentação da aç̧ão, da comunicação e da decisão. Lisboa: Universidade Católica.

Matheus, Renato Fabiano (2005). Rafael Capurro e a filosofia da informação: abordagens, conceitos e metodologias de pesquisa para a Ciência da Informação. Perspectivas em Ciência da Informação, 10:2, 140-165. Retrieved from http://eprints.rclis.org/5859/1/ MATHEUSRafaelCapurroPCI2005.pdf

Silva, Armando Malheiro da, \& Ribeiro, Fernanda (2002). Das «ciências documentais» à ciência da informação: ensaio epistemológico para um novo modelo curricular. Porto: Afrontamento.

Robredo, Jaime (2007). Filosofia da ciência da informação ou ciência da informação e filosofia? : Uma questão que merece ser pensada. Retrieved from http://www.cinform.ufba.br/7cinform/ soac/papers/369a2be3343ea1ed160564371174.pdf 